\title{
Towards a Unified Theory of Fit: Task, Technology and Individual
}

\author{
Michael J. Davern \\ Department of Accounting and Business Information Systems, \\ University of Melbourne \\ email: m.davern@unimelb.edu.au
}

\begin{abstract}
Fit between task requirements, user abilities and system characteristics has both intuitive appeal and empirical support as a driver of performance with information technology. Yet despite the volume of research on the construct, there is no unified theory that encompasses the key elements of the different fit constructs. Different studies employ different definitions of fit, both conceptually and operationally. Furthermore, while greater insight is obtained by considering the dynamics of fit and performance over time, prior work has largely focused on fit as a static point-in-time construct. In this paper a unified theory of fit is developed and a comprehensive fit taxonomy is derived. Finally, the theory and definition are shown to extend to a more dynamic conceptualisation of fit.
\end{abstract}

\section{Introduction}

Predicting and explaining how information technology (IT) affects human and organisational performance is a key task for information systems (IS) researchers (e.g. Seddon, 1997; Hitt and Brynjolfsson, 1996; Delone and McLean, 1992). Such research can improve understanding of the business value impacts of information technology (e.g. Davern and Kauffman, 1998), and can yield managerial interventions and design prescriptions for more effective use of IS.

The focus in this study is how IT affects individual task performance. IT value creation becomes concrete and most controllable at the level of the individual user, within a specific task and business process context (Davern and Kauffman, 2000). At this level problems with aggregated economic measures are eliminated; and established theory bases in psychology and the cognitive sciences can be used to predict and explain human behaviour.

Fit between task requirements, user abilities and system characteristics has been shown to be a key predictor of individual performance with information systems. Notable examples include Goodhue's task-technology fit (TTF) construct 
(Goodhue and Thompson, 1995) and Vessey's (1991) cognitive fit construct. Intuitively, a better fit yields a better performance. Beyond this intuitive argument however there seems substantial divergence in the literature as to what actually constitutes 'fit'. For example, Zigurs and Buckland (1998) present 'a theory of task/technology fit' built on Venkatraman's (1989) work on fit in the strategic management literature. Surprisingly, Zigurs and Buckland do not even cite any of the work related to Goodhue's TTF construct, or Vessey's cognitive fit construct.

What is clearly required is a comprehensive theory of fit, from which it is possible to derive a taxonomy of the different types of fit that may drive individual performance with information technology. Without such a theory it is difficult to relate fit to other constructs in the literature. Moreover, without a comprehensive theory of fit the definition of the construct itself is confused. The intuitive appeal of the concept is both a key to its popularity, but also hides the lack of any comprehensive theory and definition.

To date, empirical investigations of fit have largely been static. Little is known of how fit changes over time - how users learn and systems evolve. In part, this is an artifact of the field's experience with the construct. Research logically starts with a static view because it is simpler. Understanding weaknesses of the static view can enrich subsequent efforts to develop a dynamic theory. Prior fit research has recognised the issue of dynamics, but left it unexplored. For example, Goodhue and Thompson's (1995) technology-to-performance chain model includes feedback, and Vessey and Galletta (1991) state that cognitive fit is 'an emergent property' of their model, although these dynamic aspects receive virtually no empirical attention. A dynamic theory of fit holds the prospect of identifying new interventions for improving user performance with information technologies (e.g. it could provide a basis for determining the sorts of training interventions that may be useful). It is also consistent with trends in the behavioural sciences more broadly, which have begun to focus on the explanation of behaviour as an emergent outcome of individual-environment interactions (e.g. McClamrock, 1995; Port and van Gelder, 1995; Thelen and Smith, 1994; Anderson, 1990).

The purpose of this paper is to present a comprehensive theory of fit that is explicitly able to consider the dynamic aspects of fit. The structure of the paper is as follows. Firstly, a theory and definition of fit is presented. Then, a taxonomy of the different types of fit, followed by an exploration of the dynamics of fit that draws on theory from ecological psychology, is presented. Finally, the conclusions and implications for research and practice are presented. 


\section{Fit: theory and definition}

\section{The need for a theory of fit}

Vessey and Galletta (1991) define cognitive fit as the match between task, problem representation (e.g. mode of presentation of data) and individual problem solving skills. Goodhue (1995) defines TTF as the 'extent that technology functionality matches task requirements and individual abilities'. Three components appear consistent across these two definitions: task, technology (which in Vessey and Galletta's work is what provides the problem representation) and individual abilities.

Operationally, these two widely used fit constructs are quite different. For example, the survey instrument for measuring TTF identifies 12 components (see, for example, Goodhue, 1998), whereas cognitive fit is not measured per se, but rather manipulated in experimental studies that employ the construct. While it is possible to make some mappings between the two constructs, such mappings are not the same as an integrated theory of fit. For example, one of the 12 dimensions of TTF is 'presentation', which is operationalised with items like 'data is presented in a readable and useful format' (Goodhue, 1998). This dimension may loosely capture the relationship between problem presentation and task that is at the crux of the graphs versus tables debate that cognitive fit has attempted to resolve (Vessey and Galletta, 1991). While the mapping is possible, it is still unclear theoretically what precisely constitutes a comprehensive definition of fit.

Examining fit relative to other behavioural constructs in information systems requires mapping again from scratch. There is no unifying theoretical framework to provide guidance. Consider the well-known constructs of perceived usefulness and ease of use (e.g. Davis, 1989). From a fit perspective, perceived usefulness could map into how well the technology supports the task requirements, and ease of use could correspond to the 'fit' between user abilities and the technology. While these mappings seem intuitive, there is no clear theory of fit to justify them and empirical investigation of the relationships has not been forthcoming.

\section{Components of a theory and definition of fit}

At the outset, fit has three key components - task, technology, and individual characteristics. A unified theory of fit must therefore address these components. For expositional ease, the components are described separately below, although they are inextricably linked in practice.

\section{Technology}

Following Wand and Weber (1990), a two-part view of information systems is employed here: technology-as-tool and technology-as-representation. Technology-as-tool provides the physical interface for manipulating the 
technology as representation. 'Representation' implies a model of the real world task (e.g. a mathematical model embedded in a decision support system, or a graphical representation of a document) as opposed to a designer's system metaphor or a mental model inside the head of the user. In decision support systems terms, it is the Representation part of the ROMC (Representations, Operations, Memory Aids and Controls) design approach (Sprague and Carlson, 1982).

Distinguishing between technology as tool and as representation is useful. It can help organise various literatures addressing behaviour with information technology. For example, research on the psychology of decision models (e.g. Cooksey, 1996; Hoch and Schkade, 1996; Melone et. al., 1995; Blattberg and Hoch, 1990; Kleinmuntz, 1985; Einhorn, 1972) bears on technology as representation, whereas work in human-computer interaction (e.g. Davern, 1997; Gerlach and Kuo, 1991; Norman, 1986; Card et. al., 1983) bears on understanding technology as tool.

When considering fit with technology, the question thus arises as to whether it is fit with the tool, the representation, or indeed the fit between the tool and the representation. The tool versus representation dichotomy thus provides at least one basis for conceptualising different types of fit to populate a taxonomy. Any definition of fit must be able to capture both roles of technology: tool and representation.

More broadly, the value of this tool-representation dichotomy is evident in considering other behavioural constructs in the information systems literature. Consider the well-known constructs of ease-of-use and perceived usefulness from the technology acceptance model (Davis, 1989). Does the ease-of-use pertain to the technology as tool or as representation? Likewise for the usefulness construct. By capturing the dichotomy explicitly in a theory and taxonomy for the fit construct there is no such confusion.

\section{Task}

Following Wood (1986), task is defined here as comprising three components: products, required acts, and information cues. Products are ends, required acts and information cues are means for achieving the ends or goals. Specification of products or goals should detail the level of performance (in other words, the quality of the product, such as the accuracy of a sales forecast). Behavioural requirements (acts to be carried out and information cues to be used) will vary with the level of performance required in the task product. In practice there may often be substantial choice amongst sets of required acts (more than one way to achieve the goals of the task), even given a specific target level of performance. 
The decomposition of task into goals and acts can be carried even further. User interactions with computer-based systems have often been described in terms of a hierarchy of tasks (Gerlach and Kuo, 1991; Card et. al., 1983). Rasmussen (1988) identified three levels of abstraction for computer supported work tasks: functional purpose, generalised, and physical (for an application of this framework in information systems, see Davern, et. al., 2000). In a similar vein, Silver (1990) distinguished between mechanical and conceptual tasks in decision support system usage.

To illustrate the task hierarchy consider the example of producing a sales forecast. There is the substantive task for which the product is the sales forecast. The required acts and information cues for making the forecast could involve collating and modelling a sizable time series of past sales. The size of the time series (the information cues) and the collation and modelling efforts (required acts) are contingent on the level of performance at which the product (sales forecast) is defined (i.e. the desired accuracy). Typically, the task leads the human forecaster to use some computer-based aid. Using technology support to produce a forecast involves running the time series data against some forecasting model. Thus there is the task that has as its product a computer model of sales (a sub-task of the substantive task), which involves the technology as representation. Subordinate to this task are the series of sub-tasks the products of which are specifications of some part of the model inside the computer or refinements to it (e.g. adding variables, etc). There is also a series of subtasks, the product of which is the time series data in a form suitable for running against the model. These more operational tasks involve the use of technology as a tool rather than as a representation, and are a primary concern of human-computer interaction research.

The type of fit and relevant measures of performance vary with the level at which a task is defined. At a minimum, it is necessary to distinguish among three key levels in the task hierarchy. There is the level of the super-ordinate or substantive task that motivates the whole exercise (e.g. producing a sales forecast). There is also the level of the computer modelling task ${ }^{1}$ which involves the technology as representation (e.g. conceptual development and manipulation of a sales forecasting model inside the computer). Finally, there is the level of the more operational tasks in the hierarchy that involve the use of technology as a tool (e.g. data entry and other more physical operations). It is also evident that different users will work on different and multiple tasks and sub-tasks at different stages of interaction with an information system. By way of example, Figure 1 depicts a sample task hierarchy for a production mix optimisation problem using the spreadsheet package Excel.

\footnotetext{
1 The term modelling is used here in its broadest sense. Even when using a word processor there is a 'model' being developed that corresponds, ultimately, to the paper document that gets printed.
} 


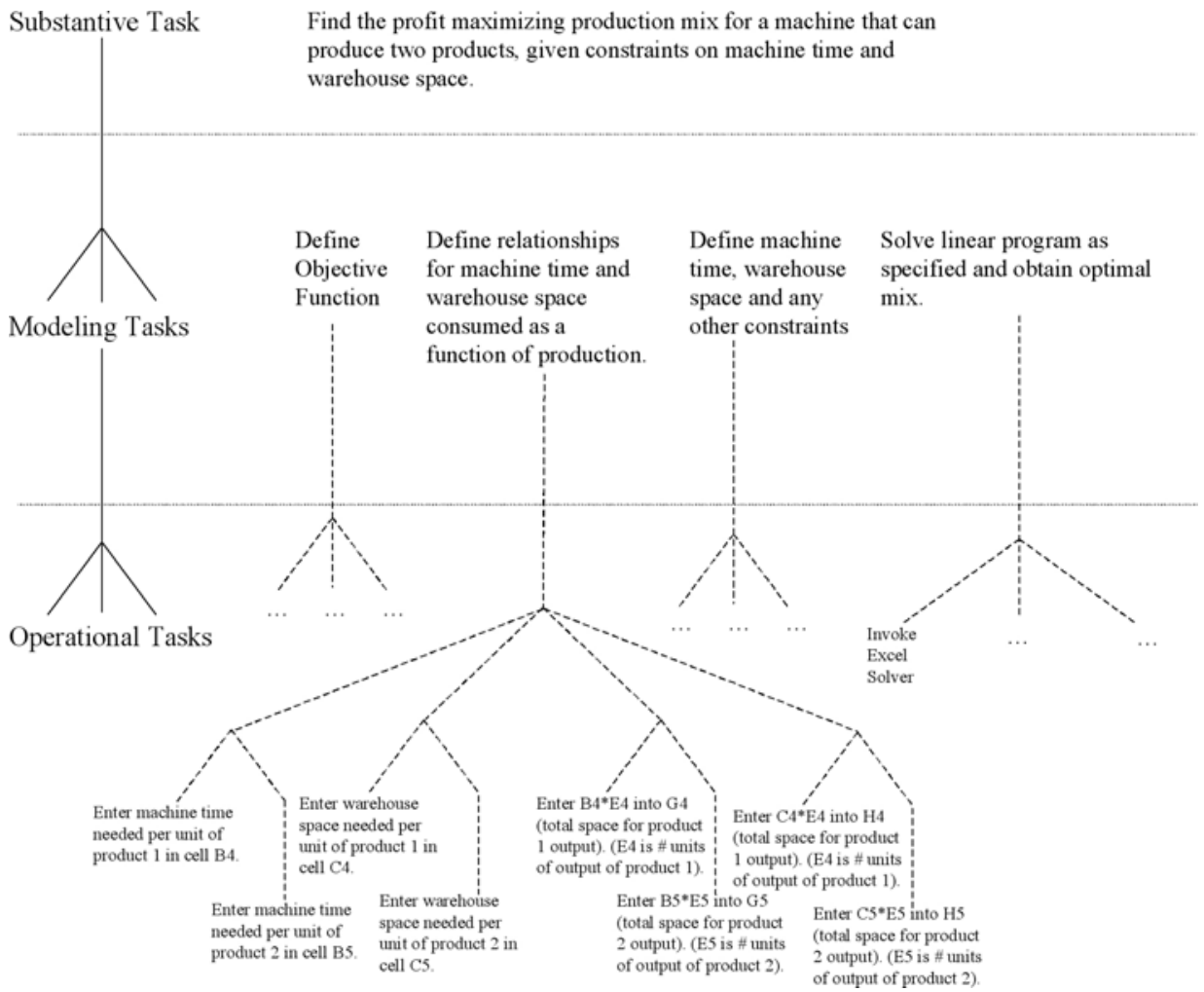

Figure 1: Task Hierarchy for solving a production mix problem using Excel.

\section{Individual user}

Newell (1982) provides a framework by which it is possible to understand individual behaviour in terms of knowledge and goals - the principle of rationality - which states:

If an agent has knowledge that one of its actions will lead to one of its goals, then the agent will select that action (Newell 1982, p. 102).

In simple terms, if an individual's goals are known then from observing their behaviour his knowledge can be inferred. Alternatively, if the goals and knowledge of an individual are known his behaviour can be predicted. ${ }^{2}$ Newell's framework complements the definition of task in terms of products, required acts and information cues presented above. Products are goals. Information cues and required acts define the structure of the task to which the individual user

\footnotetext{
${ }^{2}$ While this may appear to be a circularity, Anderson (1990) demonstrates this not to be the case as he notes: 'if we know a person's goals and observe his behaviour, we can infer his knowledge. Now that we have determined his knowledge, if we manipulate his goals, we should be able to predict his new behaviour ... [we] infer knowledge from one situation and make potentially disconfirmable predictions in a new situation. The appearance of circularity is only illusory.'
} 
must apply their knowledge and abilities. Thus, such questions arise as: Does the user have the knowledge to carry out the required acts? Does he or she have the requisite knowledge to effectively utilise relevant information cues? Does the user's knowledge and abilities about how to achieve the task goal/product correspond to the set of acts and information cues supported by the technology?

To understand behaviour (and ultimately performance) with information technology thus requires understanding both the goals and the knowledge of the user. Importantly, this does not require absolute definition of how an individual will achieve a goal. The Principle of Equifinality (McClamrock, 1995) suggests that there are multiple ways to achieve a given goal or product. Colloquially, this is often rendered as 'there is more than one way to skin a cat'. Equifinality and the task hierarchy suggest that multiple actions may achieve a goal and there may be multiple goals implying different actions. Thus, the principle of rationality simply constrains actions, rather than dictates them. This degree of flexibility and equifinality evident in the application of the principle of rationality will prove important in understanding fit as a dynamic emergent property of user-technology interactions, as discussed in section four below.

\section{Fit defined}

Any definition of fit must consider task (goals/products, required acts, and information cues), technology (tool and representation, both of which support finite sets of goals, acts and relevant information cues), and user (goals, knowledge of how to carry out relevant acts and knowledge of how to make use of relevant information cues). It must also be consistent with the principle of equifinality. In its most general form fit is defined here as:

An agent's potential to achieve a given performance level at a given task.

Notably, the definition is silent on the mechanics of how potential becomes performance, which is consistent with the principle of equifinality. The distinction between fit and performance is somewhat analogous to the distinction in physics between the potential energy of a ball about to be dropped and the kinetic energy of the ball in motion, having just been dropped. More formally, it draws on Chomsky's (1965) classic distinction between competence and performance theories of behaviour that is the foundation of much of modern linguistics. Competence, as used by Chomsky, defines the capability for idealised performance. Performance is the realisation of this capability, which in practice may not quite achieve the full potential.

The general definition above is purposely couched in terms of an 'agent'. Changing the agent in question provides a basis for generating different types of fit. For example, the agent may be the individual user, the technology-as-tool or the technology-as-representation. The roots of this definition are in the broader 
cognitive science literature, where Johnson et al. (1992) provide a powerful definition of the fit a cognitive agent has with their task environment:

Fit, then, characterises the degree to which an agent's expertise (a) reflects the requirements for success in ... performing tasks and (b) is in accordance with the structure of available task information. (p. 307)

Adapting Johnson et al's definition to the present context, fit is formally defined here as:

Fit: The degree of functional correspondence between an agent's knowledge and the structure and features of the environment that specify supported actions and available information, relative to a specific task.

With its roots in psychology (e.g. Gibson, 1979; Kochevar, 1994) this definition lends itself to a theory of dynamics as discussed below. Importantly, it can also be readily mapped on to the different components of fit described earlier.

\section{A fit taxonomy: the ATT-Fit framework}

Fit, then, is a mapping amongst the required acts and information cues of a task, an agent's knowledge of relevant acts of which they are capable and information they can interpret and use, and finally the acts supported and information provided by the environment. The term 'environment' here refers conceptually to the location in which the task is carried out. Given the three levels of the task hierarchy, it logically follows that there are three 'task-environments'. The environment for the substantive task is reality - the real world context of the task. Similarly, the environment for the modelling task is the technology as representation. Finally, the environment for the operational task is the technology as tool. Table 1 summarises the taxonomy of different fits that arise in considering the different agents and task-environment combinations. Figure 2 summarises this visually in the ATT-Fit framework: A framework of Agent-Task-Technology Fit. The figure succinctly demonstrates that the taxonomy is exhaustive (all possible combinations are included).

\begin{tabular}{lll}
\hline Agent & Task-Environment & Type of Fit \\
User & Substantive-Reality & User-Reality Fit \\
& Modelling-Representation & User-Representation Fit \\
& Operational-Tool & User-Tool Fit Fit \\
Technology (Representation) & Substantive-Reality & Representation-Reality Fit \\
Technology (Tool) & Modelling-Representation & Tool-Representation Fit \\
& Substantive-Reality & Tool-Reality Fit \\
\hline
\end{tabular}

\section{Table 1: A fit taxonomy}

Interestingly, technology can play a role as both agent and environment. This role is twofold again because it can play agent or environment either as tool or as representation. In theory, therefore, the technology can be both agent and environment. In practice, this can be simplified by recognising that tools may 
act on representations, but not the other way around. Consequently, the only task-environment for technology as representation is reality - at the substantive task level.

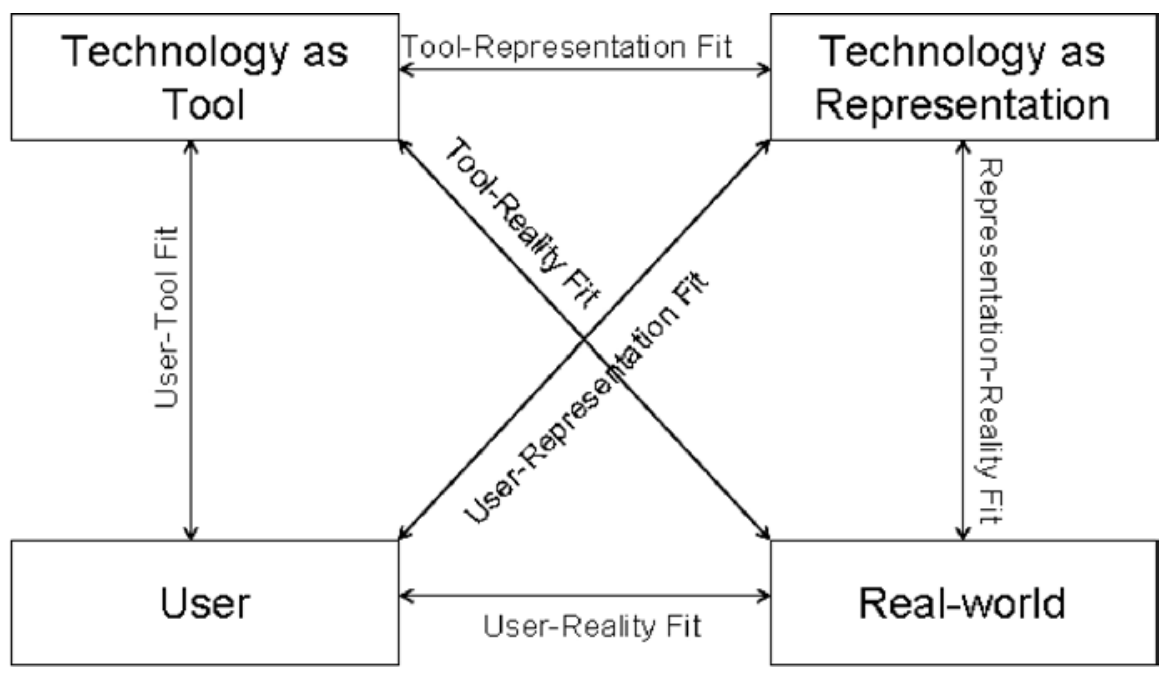

Figure 2: Visualising the fit taxonomy: the ATT-Fit framework.

\section{Defining the different types of fit}

User-Reality fit is the functional correspondence between the user's knowledge of the relevant set of acts and information cues that could achieve the task goals (e.g. a sales forecast) and the actions supported and information available in the organisational and business process context of the user's work (the substantive-task/real-world task environment). It is the user's potential for substantive task performance, unaided by technology.

User-Representation fit pertains to the user's potential performance in the modelling task (e.g. producing a sales forecast from a computer-based model). It is the degree of functional correspondence between the user's knowledge of the set of acts (e.g. model manipulation and analysis) and information cues (variables) that could achieve the desired goal (e.g. a computer based sales forecast and associated model). The task-environment here is the modelling task/technology-as-representation (e.g. the variables in the model and the analysis methods supported by the model's formulation).

User-Tool fit pertains to the user's potential performance in the operational task. It is a measure of the functional knowledge the user has of the acts and information cues supported by the technology-as-tool in carrying out operational tasks (i.e. a correspondence between what is known by the user and what is supported by the tool). Such knowledge, for example, could include the 
commands to execute data and model manipulation tasks in the sales forecasting scenario).

Representation-Reality fit is the degree of functional correspondence between the technology as representation's knowledge of relevant acts and information cues relative to the required acts and information cues of the substantive task (e.g. sales forecasting), in reality. It is the system's potential for performance, assuming it is effectively used. For example, in a decision support system, representation-reality fit is a measure of how well the model embedded in the decision support system functionally approximates the real world decision environment.

Tool-Representation fit is the tool's potential performance in manipulating the representation (i.e. the modelling-representation task-environment). It is the degree of functional correspondence between the representation manipulation and processing acts supported by the tool, and the acts required in manipulating the representation to achieve the modelling task goal (e.g. an appropriately specified sales forecasting model and suitably organised time series data).

Tool-Reality fit recognises that the demands of the modelling task are somewhat determined by the demands of the substantive task. Consequently, it is the tool's potential for manipulating appropriate representations of reality. Tool-Reality fit is the degree of functional correspondence between the technology as tool's knowledge of (support for) procedures of data and model manipulation that are implied by the substantive task, and consistent with the actions and information supported in real-world context (i.e. the substantive-reality task-environment).

\section{Performance and the ATT-Fit framework}

When considering the fit to performance relationship it is necessary to identify the specific task-environment of interest - the goals of the task and its place in the hierarchy of operational tasks, modelling tasks, substantive tasks. Indeed, location in the task hierarchy determines the relevant set of performance measures. In practice, performance is a multi-attribute construct; it can rarely be defined in terms of a single all encompassing measure (in part because good measures are often hard to come by, and in part because users have multiple goals to satisfy).

In its most general form, performance can be measured in terms of effectiveness and efficiency. Effectiveness relates to the output quality of the task (the task as product). Efficiency relates to the costs of inputs (information cues, required acts) for a given level of output (product). At higher levels in the task hierarchy, effectiveness measures dominate user attention. For example, in the substantive task of producing a sales forecast, forecasting accuracy is the key performance measure. Of course, the forecast must be completed in reasonable time (i.e. the required acts cannot be too onerous) and the relevant data must be readily 
available at a reasonable price (i.e. the information cues employed must be accessible economically), but these are matters of efficiency. At the higher hierarchical levels these efficiency performance measures act more as minimum requirements that, once satisfied, become relatively inconsequential. For example, the time it takes (a function of the required acts) to produce the sales forecast will not be of consequence unless it delays the production of the forecast past the point when management can act on the information. This is not to say that the manager will not prefer tools that take less time (e.g. require fewer keystrokes to manipulate data or models). Rather, it suggests that in the context of the super-ordinate task of producing a good forecast, enhanced modelling and data manipulation capabilities are likely to be more important than interface improvements (within some 'reasonable' limits).

In contrast, at lower levels in the task hierarchy efficiency issues take on greater importance (e.g. operations such as downloading files, printing documents, or booting up a machine always seem to take too long). Thus, at lower levels in the task hierarchy efficiency measures become more important, largely because effectiveness (product or output) performance tends to be binary (e.g. either the document printed out correctly or it did not, the data were sorted appropriately or not).

For each of the three key tasks in the task hierarchy, performance can be more formally defined as a function of the different fits, in principle, as follows:

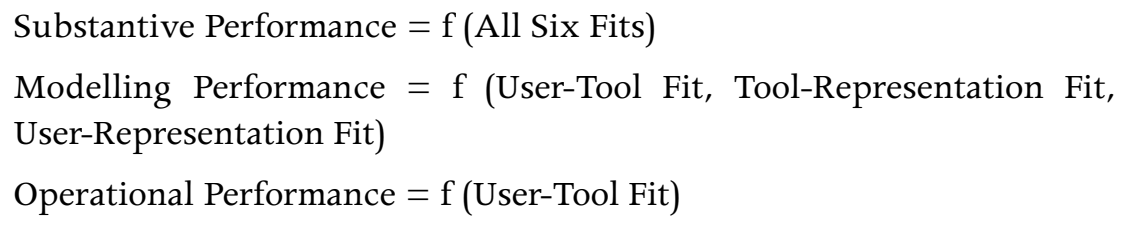

More completely, any fit based predictions and explanations of performance must recognise the dynamic nature of fit. Fit is subject to change over time as users learn and systems are refined. Pragmatically, it is also important to recognise that perceptions of fit may often differ greatly from what is actually the case (Davern, 1996; 1999).

\section{A dynamic view of fit}

Under a dynamic view, fit is an emergent property of an interaction between adaptive knowledge agents and the properties of the task environment that specify relevant information cues and required behavioural acts. Fit changes over time as the agent learns and the task environment changes. To understand fit as an emergent property requires analysis of the feedback system from which it emerges. Such an analysis considers the effects of both user learning and system evolution on performance - two critical factors that are not readily accommodated by simply considering the state of fit at a given point in time. 
Although prior IS research on fit has recognised in theory that feedback is important (e.g. Goodhue and Thompson, 1995), feedback has not been the main focus of study either theoretically or empirically (e.g Goodhue, 1998; Vessey and Galletta, 1991; Umanath and Vessey, 1994; Goodhue, 1995).

Prior research on behaviour with information technology evidences the value of understanding the dynamics of technology usage. For example, DeSanctis and Poole's (1994) Adaptive Structuration Theory (AST) takes a dynamic process view of technology usage. AST suggests that the way in which a technology may be used is not deterministic but rather adaptive. AST views behaviours in using technology as emerging from interactions between users and technology features. Thus, a technology may be used in a variety of ways, not necessarily consistent with the intentions of the system designers, which may constitute what DeSanctis and Poole (1994) call unfaithful appropriations of the technology. Importantly, DeSanctis and Poole also note that 'unfaithful appropriations are not "bad" or "improper" but simply out of line with the spirit of the technology' (DeSanctis and Poole, 1994). Unfaithful appropriations suggest that achieving a good fit is not simply a matter of engineering; rather it emerges from user interactions with the system. Other research has shown the value of conceptualising technology usage as adaptive and exploratory behaviour (e.g. Davern and Wilkin, forthcoming; Bagozzi et al.,1992; Seely Brown, 1986). A dynamic theory of fit could thus provide improved explanations of the behaviour and performance outcomes in technology usage that involve user learning and adaptive usage - for both faithful and unfaithful appropriations.

\section{Dynamic fit: an ecological psychology theory}

As a scientific concept, fit has its origins in the biological sciences where the emphasis is on understanding the process of fitting in order to understand the fit that emerges. Evolutionary selection is viewed as a process of survival of the fittest. In this evolutionary context, the explanatory power of fit is not so much in the outcome of the process of fitting (i.e. selection of some biological feature of a species) as in the process itself; that is, in how the biological feature came to be selected in the evolutionary process (see, for example, Dawkins, 1982). In a human behavioural context, as opposed to a purely biological context, ecological psychology has explored the dynamic and emergent nature of fit (e.g. Kochevar, 1994). The definition of fit presented earlier can be shown to be entirely consistent with the concept of dynamic fit in ecological psychology.

In ecological psychology behaviour is the product of the interaction between an individual and the environment. Gibson (1979) coined the term affordance to refer to the possible actions that may result from this interaction between an individual's knowledge and the properties of the environment. A situation can afford a particular action for an individual with appropriate knowledge and abilities, and an individual can have the knowledge and abilities to carry out a 
particular action in an environment that affords such actions (Greeno et al., 1993). As Kochevar (1994) puts it: 'Environments provide information structured to support specific behaviours, and adapted individuals are sensitive to such information patterns'. Thus, the concept of an affordance is concerned with the complementarities between an agent's knowledge and abilities and the features of the environment (i.e. the information it provides and actions it supports). This notion of complementarities is essentially one of fit, but 'fitness' for what purpose? A given environment may afford many different actions for agents of even limited abilities. Affordances do not determine action; they merely define the set of possible actions available to a given agent in a particular environment. Newell's Principle of Rationality, discussed earlier, provides the 'filter' for action selection: an agent will select the action (realise the affordance) that appears to best attain his or her task goals. Indeed, Heft (1989) states that the affordances an individual perceives in a given environment are determined by his or her intentions or goals. Notably, the other aspects of task, information cues and required acts, relate to the affordances themselves - what information the environment provides and what actions it supports.

Ecologically, what a situation affords an individual at a given point in time depends on the fit amongst the individual's knowledge and abilities, the actions supported by the environment and the information it provides, in the context of the task goals that are present. Thus, the earlier definition of fit as the degree of the correspondence between an individual's knowledge and the structure and features of the environment that specify supported actions and information, in the context of a specific task goal, is entirely consistent with ecological psychology principles. The complementarities between the environment (information cues provided and actions supported) and an individual's knowledge define the set of all possible actions the individual may take in that environment - the affordances. The task at hand (goals, required acts and information cues) determines what affordances an agent perceives in that environment at a given point in time. More specifically, the task goals serve as a filter in the selection of the appropriate action to take. At least implicitly, this filtering reflects the degree of fit amongst the environment (information provided and acts supported), the agent's knowledge (ability to use information and carry out acts), and the demands of the task (goals, required acts, and information cues - of which goals is the most determinative element since equifinality implies substitutions may be possible with respect to acts and cues).

This filtering is not a cognitively complex task. Rather, ecological psychology argues the somewhat extreme position that individuals 'directly perceive' the task relevant affordances in an environment. As Gibson (1979) notes:

Perceiving is an achievement of the individual, not an appearance in the theater of his consciousness. It is a keeping-in-touch with the world, an 
experiencing of things rather than a having of experiences. It involves awareness-of instead of just awareness.

Ecologically speaking individuals engage in a continuous perception-action cycle as they seek to maintain the fit between their knowledge and the environment in their attempts to satisfy specific task goals - fit is dynamic and task specific. Maintaining fit is a process of becoming sensitised to the affordances in a given environment and task context, and of fine-tuning this sensitivity. Problem solving behaviour can be characterised as 'gap closing' (Lave, 1988); attempting to improve the fit between the individual's knowledge and the environment in the task context. Gap closing involves taking the processes used in the past to handle similar classes of problems or tasks and iteratively manipulating them until the present task or problem can be accomplished or resolved.

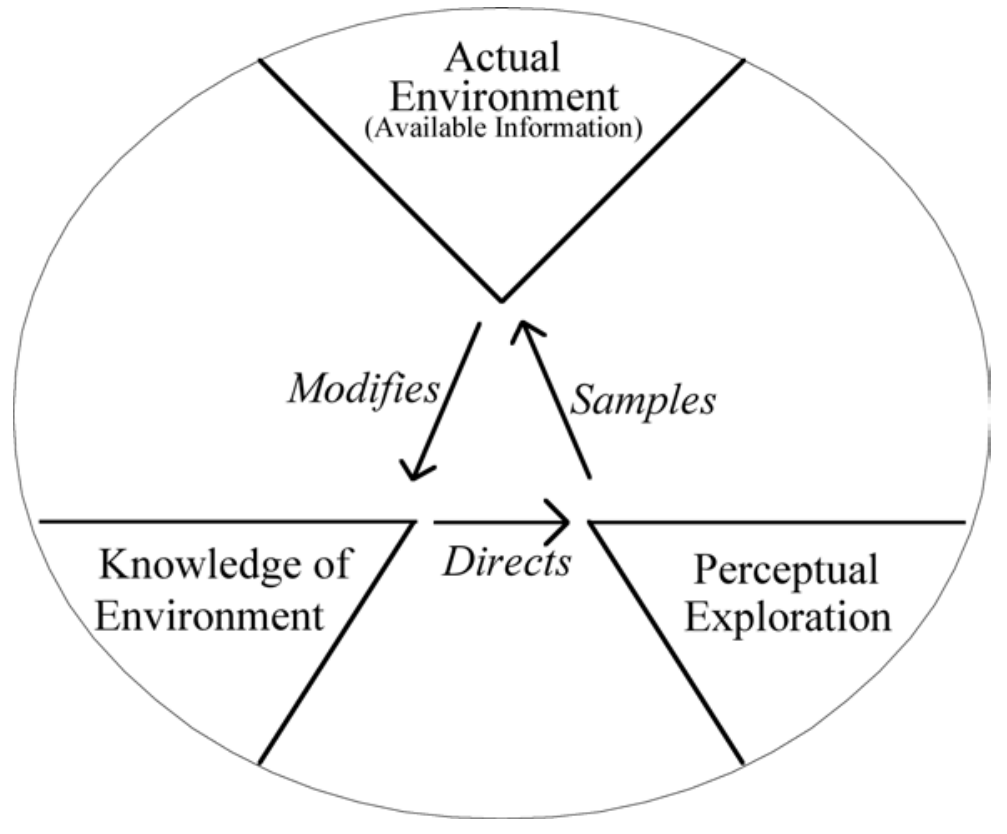

Figure 3: Neisser's perceptual cycle (adapted from Neisser, 1976).

Neisser's (1976) Perceptual Cycle characterises this gap closing process (see Figure 3). The individual has some knowledge of the environment based on past experiences. This knowledge drives exploratory action in the actual environment; for example, behaviour driven by a crude notion such as 'my experience suggests that this [action] usually fixes problems like this' (Orr, 1990). Feedback about the success of the action relative to the goals results in modifications to the individual's knowledge (their sensitivity to the affordances of the environment is fine-tuned) that then drives further action. This process iterates until the individual is satisfied that his or her knowledge of the environment and the actions that derive from it adequately address the problem (i.e. the task can be 
completed). Satisfactory fit is achieved. Importantly, this conception of fit allows for new and unique combinations of actions to emerge (Kochevar, 1994). In AST terms, it allows for novel, unique and unexpected or 'unfaithful' appropriations of a technology environment.

\section{Judgments of fit: implications for learning and systems change}

Neisser's perceptual cycle is essentially a model of learning. Learning is thus an integral component of a dynamic, ecological view of fit. As an individual learns more about the environment, his or her fit with it changes and the affordances (possible actions) available change. Old ways of doing things are supplanted by new and better ways. However, in technology supported work environments, there are multiple types of fit, as there are multiple knowledge agents (user, technology-as-tool, technology-as-representation as per Table 1). While an individual may be able to 'directly' perceive affordances and consequently their fit with an environment for a given task, the assessment of fit for an agent other than themselves (e.g. as in representation-reality fit) is clearly a more cognitively complex task.

From a cognition perspective, two information processes influence an individual's judgments of fit: inference from past performance, and prospective analysis of available affordances in light of one's goals. Both of these processes can introduce errors into fit judgments. For example, performance feedback is often delayed in real world environments. Moreover, it is also difficult for an individual to causally separate performance variations due to actions taken from those due to natural variation in a stochastic world. Indeed, prior research has shown that human decision makers do not cope well with dynamic feedback systems, particularly when there are delays (Diehl and Sterman, 1995; Sterman, 1989a; 1989b).

Inferring fit from a goal-based consideration of available affordances as a form of prospective thinking - evaluating the desirability of realising an available affordance without actually taking the action - is also subject to error and bias as it is likely to be carried out heuristically (e.g. Tversky and Kahneman, 1974). The problem is exacerbated when a user is inferring fit when the technology is the knowledge agent. For example, assessing representation-context fit requires that the user have knowledge of what the environment affords the representation. Consequently, this implies that the accuracy of subjective judgments of representation-reality fit by a user is influenced by the degree of user-representation fit. $^{3}$

3 There is already support for this notion in the literature. Melone et al. (1995), following Sharda et al. (1988), attribute the conflicting performance outcomes in experimental DSS studies to the influences of differences in user knowledge of the system model (representation) on users' abilities to appropriately calibrate their use of a DSS. 
Judgments of fit, whether directly perceived or otherwise, drive individual learning and motivate efforts in task or systems refinement and development. Learning in this dynamic view of fit can be proactive, reactive, or passive. Proactive learning aims at improving fit by making available to the individual new affordances. It is driven a priori on an assessment of how well the current affordances correspond to the individual's goals. Reactive learning occurs in response to dissatisfaction with the performance evaluation of actions taken. Learning can also occur passively as an individual acquires knowledge in a non-purposeful manner while interacting with the environment. In the information systems context, proactive learning could occur when a user works through an interactive tutorial before attempting a task with a new piece of software. Reactive learning could occur through resorting to the tutorial after having difficulties carrying out a task with a new piece of software. Passive learning could occur when a user discovers new ways of using a software application through casual observation or interaction with another user - it is merely an incidental outcome rather than a deliberate goal of the user.

Judgments that fit is unsatisfactory can also lead to efforts to change the environment to improve fit; through system refinement and development, for example. Such efforts could be as radical as a major hardware or software upgrade, or as simple as a change to the toolbars displayed in a word processor. Importantly, these changes may also occur exogenously if they are imposed on users rather than instigated by them.

Since users' inferences about the different types of fit can become biased, their subjective judgments of fit may differ substantially from more objective measures of fit. In the IS context this is problematic both for the user who seeks to maximise job performance through IT and for the researcher or practitioner trying to evaluate a system. More specifically, misjudgements that fit is good, when it is not, reduce the motivation for learning (as per the perceptual cycle) or to refine a system to improve fit. In a similar vein misjudgements that fit is bad when it is actually good (such as may occur in highly stochastic environments) could lead to unwarranted efforts at system refinement or task learning.

\section{Implications and conclusions}

\section{Theoretical contributions}

A unified theory of fit has been developed and a comprehensive definition has been derived from the theory. The definition recognises the key aspects of technology, individual, and task that are present in prior research. It also provides the basis for an explicit description of a taxonomy of the different types of fit in technology supported work and the interrelationships amongst them. 
Furthermore, it has demonstrated theoretically that performance and fit are distinct but related constructs.

The theory and definition of fit developed in the paper is shown to be consistent with a move to a dynamic understanding of fit. The development of theories of the feedback processes and dynamics of fit and performance over time is itself a promising and under-researched area, but a direction consistent with trends in the broader behavioural sciences literature to consider the dynamics by which behaviour emerges over time (e.g. Port and Van Gelder, 1995; Sterman, 1989a; 1989b). It also highlights the potential for user misjudgements of fit (Davern, 1996; 1999).

\section{Practical implications}

One of the difficulties facing both researchers and practitioners in using the various behavioural of constructs in information systems is understanding precisely what is being measured. The taxonomy of fits in the ATT-Fit framework serves as a useful foundation in this regard. It clearly articulates a basis for distinguishing between different types of fit. For example, it highlights some of the distinctions (e.g. between technology as representation and as tool) that are glossed over by existing measures of fit, and indeed a number of other widely used IS constructs.

More specifically, the explication of the task hierarchy calls practitioners and researchers alike to specifically identify the task for which they anticipate the technology will provide performance gains. Alternatively, it serves as a diagnostic tool for identifying where a technology solution may be failing. Again, it provides a clear and theoretically grounded foundation for understanding the different aspects of fit in information technology contexts.

Finally, the richer understanding of behaviour with technology provided by the dynamic conceptualisation of fit may lead to new and more successful methods and interventions in systems and training that are cognisant of these dynamics.

\section{References}

Anderson, J. R. 1990, The Adaptive Character of Thought, Hillsdale, NJ, L. Erlbaum Associates.

Bagozzi, R. P., Davis, F. D. and Warshaw, P. R. 1992, 'Development and test of a theory of technological learning and usage', Human Relations, vol. 45, no. 7, pp. 659-86.

Blattberg, R. C. and Hoch, S. J. 1990, 'Database models and managerial intuition: $50 \%$ model $+50 \%$ manager', Management Science, vol. 36, no. 8, pp. 887-99. 
Card, S., Moran, T. and Newell, A. 1983, The Psychology Of Human-Computer Interaction, Hillsdale, NJ: Lawrence Erlbaum and associates.

Chomsky, N. 1965, Aspects Of The Theory Of Syntax, M.I.T. Press, Cambridge.

Cooksey, R. W. 1996, Judgment Analysis: Theory, Methods, And Applications, San Diego, CA, Academic Press.

Davern, M. J. 1996, 'When good fit is bad: The dynamics of perceived fit', Proceedings of the Seventeenth International Conference on Information Systems, Cleveland, $\mathrm{OH}$.

Davern, M. J. 1997, 'Human-Computer Interaction', in Davis, G. B. (ed.), Blackwell's Encyclopaedic Dictionary of Management Information Systems, Blackwell, Oxford, UK, pp. 98-99.

Davern, M. J. 1999, 'Performance with information technology: Individual fit and reliance on decision support systems', unpublished doctoral dissertation, University of Minnesota.

Davern, M. J. and Kauffman, R. J. 2000, 'Discovering Value and Realising Potential from IT Investments', Journal of Management Information Systems, vol. 16, no. 4, pp. 121-44.

Davern, M. J., Te'eni, D. and Moon, J. 2000, 'Content versus structure in information environments: A Longitudinal analysis of website preferences', Twenty-First International Conference on Information Systems, Brisbane, Australia.

Davern, M. J. and Wilkin, C. L. Forthcoming, 'Evolving Innovations Through Design and Use', Communications of the ACM.

Davis, F. D. 1989, 'Perceived usefulness, perceived ease of use, and user acceptance of information technology', MIS Quarterly, vol. 13, no. 3, pp. 31940.

Dawkins, R. 1982, The Extended Phenotype. San Francisco, CA, W. H. Freeman.

Delone, W. H. and McLean, E.R. 1992, 'Information systems success: The quest for the dependent variable', Information Systems Research, vol. 3, no. 1, pp. 60-95.

DeSanctis, G. and Poole, M. S. 1994, 'Capturing the complexity in advanced technology use: Adaptive structuration theory', Organisation Science, vol. 5, no. 2, pp. 121-47.

Diehl, E. and Sterman, J. D. 1995, 'Effects of feedback complexity on dynamic decision making', Organisational Behavior and Human Decision Processes, vol. 62, no. 2, pp. 198-215.

Einhorn, H. J. 1972, 'Expert measurement and mechanical combination', Organisational Behavior and Human Performance, vol. 7, no. 1, pp. 86-106. 
Gerlach, J. H. and Kuo, F-Y., 1991, 'Understanding human-computer interaction for information systems design', MIS Quarterly, vol. 15, no. 4, pp. 52749.

Gibson, J. J. 1979, An Ecological Approach to Visual Perception. Boston, MA: Houghton Mifflin.

Goodhue, D. L. 1995, 'Understanding user evaluations of information systems', Management Science, vol. 41, no. 12, pp. 1827-44.

Goodhue, D. L. 1998, 'Development and measurement validity of a task-technology fit instrument for user evaluations of information systems', Decision Sciences, vol. 29, no. 1, pp. 105-38.

Goodhue, D. L. and Thompson, R. L. 1995, 'Task-technology fit and individual performance', MIS Quarterly, vol. 19, no. 2, pp. 213-36.

Greeno, J. G., Moore, J. L. and Smith, D. R. 1993, 'Transfer of situated learning', in Detterman, D. K. and Sternberg, R. J. (eds), Transfer on Trial: Intelligence, Cognition and Instruction, Norwood, NJ, Ablex Publishing Co.

Heft, H. 1989, 'Affordances and the body: An intentional analysis of Gibson's ecological approach to visual perception', Journal for the Theory of Social Behaviour, vol. 19, no. 1, pp. 1-30.

Hitt, L. M. and Brynjolfsson, E. 1996, 'Productivity, business profitability, and consumer surplus: three different measures of information technology value', MIS Quarterly, vol. 20, no. 2, pp. 121-42.

Hoch, S. J. and Schkade, D. A. 1996, 'A psychological approach to decision support systems', Management Science, vol. 42, no. 1, pp. 51-64.

Johnson, P. E., Kochevar, L. K. and Zaulkernan, I. 1992, 'Expertise and fit: Aspects of cognition', in Pick, Jr., H. L., Van den Broek, P. and Knill, D. C. (eds) Cognition: Conceptual And Methodological Issues, pp. 305-331. Washington, DC: American Psychological Association.

Kleinmuntz, D. N. 1985, 'Cognitive heuristics and feedback in a dynamic decision environment', Management Science, vol. 31, no. 6, pp. 680-702.

Kochevar, L. K. 1994, 'Generativity of Expertise', unpublished doctoral dissertation, University of Minnesota.

Lave, J. 1988, Cognition in Practice: Mind, Mathematics and Culture in Everyday Life, New York, NY, Cambridge University Press.

McClamrock, R. A. 1995, Existential Cognition: Computational Minds in the World, Chicago, IL: Chicago University Press.

Melone, N. P., McGuire, T. W., Chanand, L. W. and Gerwing, T. A. 1995, 'Effects of DSS, modelling, and exogenous factors on decision quality and con- 
fidence', Proceedings of the Twenty-Eighth Hawaii International Conference on System Sciences, Wailea, HI, pp. 152-9.

Neisser, U. 1976, Cognition and Reality: Principles and Implications of Cognitive Psychology, San Francisco, CA, W. H. Freeman.

Newell, A. 1982, 'The knowledge level', Artificial Intelligence. vol. 18, no. 1, pp. 87-127.

Norman, D. A. 1986, 'Cognitive engineering', in Norman, D. A. and Draper, S. W., (eds) User Centered System Design: New Perspectives on HumanComputer Interaction, pp. 31-61. Hillsdale, NJ: Lawrence Erlbaum and Associates.

Orr, J. E. 1990, 'Sharing knowledge, celebrating identity: Community memory in a service culture', in Edwards, D. and Middleton, D. (eds), Collective Remembering: Inquiries In Social Construction, pp.169-89. London, Sage Publications.

Port, R. F. and van Gelder, T. 1995, Mind As Motion: Explorations In The Dynamics Of Cognition, Cambridge, Mass., MIT Press.

Rasmussen, J. 1988, 'A cognitive engineering approach to the modelling of decision making and its organisation in: process control, emergency management, cad/cam, office systems, and library systems', Advances in Man-Machine Systems Research, vol. 4, pp. 165-243.

Seddon, P. B. 1997, 'A re-specification and extension of the DeLone and McLean model of IS success', Information Systems Research, vol. 8, no. 3, pp. 240-53.

Seely Brown, J. 1986, 'From cognitive to social ergonomics and beyond', in Norman, D. A. and Draper, S. W. (eds), User Centered System Design: New Perspectives on Human-Computer Interaction, pp. 457-486. Hillsdale, NJ: Lawrence Erlbaum and Associates.

Sharda, R. M., Barr, S. H. and McDonnell, J. C. 1988, 'Decision support system effectiveness: A review and empirical test', Management Science, vol. 34, no. 2, pp. 139-59.

Silver, M. S. 1990, 'Decision Support Systems: Directed and non-directed change', Information Systems Research, vol. 1, no. 1, pp. 47-70.

Sprague, R. H. and Carlson, E. D. 1982, Building Effective Decision Support Systems, Englewood Cliffs, N.J., Prentice-Hall.

Sterman, J. D. 1989a, 'Misperceptions of feedback in dynamic decision making', Organisational Behavior and Human Decision Processes, vol. 43, no. 3, pp. 301-35. 
Sterman, J. D. 1989b, 'Modelling managerial behavior: Misperceptions of feedback in a dynamic decision making experiment', Management Science, vol. 35, no. 3, pp. 321-39.

Thelen, E. and Smith, L. B. 1994, A Dynamic Systems Approach To The Development Of Cognition And Action, Cambridge, Mass., MIT Press.

Tversky, A. and Kahneman, D. 1974, 'Judgment under uncertainty: Heuristics and biases', Science, vol. 185, no. 4157, pp. 1124-31.

Umanath, N. S. and Vessey, I. 1994, 'Multiattribute data presentation and human judgment: A cognitive fit perspective', Decision Sciences, vol. 25, no. 5-6, pp. 795-824.

Venkatraman, N. 1989, 'The concept of fit in Strategy Research: Toward verbal and statistical correspondence', Academy of Management Review, vol.14, no. 3, pp. 423-44.

Vessey, I. 1991, 'Cognitive fit: A theory-based analysis of the graphs versus tables literature', Decision Sciences, vol. 22, no. 2, pp. 219-40.

Vessey, I. 1994, 'The effect of information presentation on decision making: An analysis using cost-benefit theory', Information and Management, vol. 27, pp. 103-19.

Vessey, I. and Galletta, D. 1991, 'Cognitive fit: An empirical study of information acquisition', Information Systems Research, vol. 2, no. 1, pp. 63-84.

Wand, Y. and Weber, R. 1990, 'Towards a deep structure theory of information systems', in DeGross, J. I., Alavi, M. and Oppelland, H. (eds), Proceedings of the International Conference on Information Systems, pp. 61-71. Copenhagen, Denmark.

Wood, R. E. 1986, 'Task complexity: Definition of the construct', Organisational Behavior and Human Decision Processes, vol. 37, pp. 60-82.

Zigurs, I. and Buckland, B. K. 1998, 'A theory of task/technology fit and group support systems effectiveness', MIS Quarterly, vol. 22, no. 3, pp. 31334. 